\title{
Self-described Attitudes and Difficulties Perceived in Mexican Police Officers
}

\author{
Roberto E. Mercadillo ${ }^{1}$, Fernando Galindo ${ }^{2}$ and Fernando A. Barrios ${ }^{1, *}$ \\ ${ }^{I}$ Institute of Neurobiology, Universidad Nacional Autónoma de México \\ ${ }^{2}$ School of Law, Universidad Autónoma de Querétaro
}

\begin{abstract}
Policing involves inter-subjective mechanisms needed to infer the violation of social values or to motivate prosocial actions. These mechanisms can be observed in the attitudes and problems that officers believe influence their work performance, but this first-person approach is not considered in recent police reforms in Mexico. We present an ethnographic examination and a psychometric evaluation with the objective of identifying attitudes and perceptions that a group of municipal police officers in Mexico formed about themselves and their institution, as well as the difficulties in their day-to-day role. Some of the fundamental qualities for being a police officer imply attitudes of risk and cooperation linked to human motivational systems denoting the welfare of others. The concepts of social welfare and cooperation can be used as ethical and motivational mechanisms during training. Social intersubjectivity is relevant since officers have legitimate permission to use coercion as a means of social justice and order. It becomes necessary to have institutional supervision, as well as training in interpersonal skills, and regulation of adverse states, which can be elicited by the apparent inconsistency between the use of coercion and the promotion of order and justice.
\end{abstract}

Keywords: Cognition, Cooperation, Policing, Stress.

\section{INTRODUCTION}

A current reality in Mexican cities are the increased criminality and the weakened ability of police to maintain social order, which has resulted in controversial reform proposals that include new controlling attributes for police officers. These types of reforms presented in several Latin American countries after the 1990s, attempt to re-think the notion of security by relating police performance to civilian perceptions and activities (Frühling, 2012).

However, only a few systematic studies about officers' behavior have been performed within the framework of the psychosocial elements linked to such attributes and the lack of security has been mostly politicized from an objective and institutional foundation (Tello, 2011). In this sense, the social responsibility of policing is attributed to the police institution; but, the officers who individually interpret the codes to achieve the authority are de facto responsible for doing so, and they affect police performance (Cruz, 2007; Toch, 2008).

Policing is based on a cultural intersubjectivity considered as being oriented towards another as another subject, and also operates through the individual's emotional and cognitive capabilities to be understood (Hollan \&

\footnotetext{
*Address correspondence to this author at the Institute of Neurobiology, Universidad Nacional Autónoma de México, Campus UNAM Juriquilla, Blvd. Juriquilla 3001, Querétaro, QRO, 76230. Mexico;

Tel: +52(442) 238-1053; Fax: +52(442) 238-1046;

E-mail: barrios@inb.unam.mx
}

Throop, 2008). Thus, the police function can be assumed under social cognition which includes introspection and perception of verbal and non-verbal own and other's cues, homeostatic autonomic and controlled processes involving emotional reactions, affective systems, and ethical and moral learning (Beer \& Ochsner, 2006). It also comprises reward systems, obtaining personal welfare while assisting other people, and the notion of social welfare typically represented in policing and linked to a legitimate limitation of individual and collective liberties in the interest of society as a whole (Mercadillo \& Arias, 2010).

Psychometric studies carried out in Mexico emphasize interpersonal support as a regulator of adverse experiences of officers, and implicate the hierarchical structure and the lack of training as two of the main problems (Aranda-Beltran, Pando-Moreno, Salazar-Estrada, Torres-Lopez, \& AldreteRodriguez, 2009). Ethnographies serve as a complement to the psychometric assessments by providing first-person testimonies of how people experience and represent their culture. In fact, police could be considered a cultural community that, being part of a broader social structure, develops distinct qualities (Suárez de Garay, 2006). In this sense, difficulties assessed for police work in Mexico must implicate the actor's perceptions to distinguish the way in which officers promote and discourage understanding of themselves, which may influence the operation of communitybased police, as well as contrast the individual and the institutional perspectives (Larose, Maddan, \& Caldero Ali Mathe, 2010; van Reenen, 2010). 
In this work we present a study performed in Nezahualcóyotl, one of the most populous municipalities of Mexico with $1,140,000$ residents distributed in a $63.44 \mathrm{~km}^{2}$ area. In contrast, only 1,850 municipal police officers comprise its Department of Public Safety (DPS). In addition to the population density, social problems in Nezahualcóyotl include its being one of the federal entities with the highest rate of violence in Mexico (Escalante, 2009). Jurisdictional disputes arise between Nezahualcóyotl and the eastern border of Mexico City and hinder the control of criminal acts committed on the boundary between the two entities see (Fig. 1). According to the information offered by the director of the Psychological Support Unit of the DPS for the purpose of the present work, officers' health problems include increasing bodyweight and consequent diseases such as diabetes and high blood pressure; gastritis, colitis and headaches are also common. With regard to the emotional sphere, officers develop their own mechanisms to regulate adverse emotions, such as anger, shame, anxiety and the decrease of empathic expressions, which are elicited by their daily activities.

In order to access the qualities and difficulties perceived by the police officers, and the relations between the officers and the institutional perspectives, we present an ethnographic qualitative examination and a quantitative psychometric evaluation on the perceptions that a group of officers formed about themselves and their institution. Our approach associates two disciplines informing the first-person reality and strategies to identify cognitive social elements in the officers' day-to-day role. The objective was to integrate psychosocial and institutional variables that affect their function.

\section{QUALITATIVE STUDY}

\section{Method}

The ethnographic analysis was based on The Grounded Theory, which elaborates notions about the social world based on symbolic interactionism. According to this theory people act over the environment agreeing to the understanding they have of the environment's elements; the meaning of these elements emerges from social interactions with other people, and these meanings are used and transformed through interpretative processes that people use to face specific situations (Charmaz, 2005).

The ethnographic approach began with general questions that emerged from both the researchers' interest on social cognition and the concern of the Direction of Public Safety of Nezahualcóyotl Municipality about previously observed hostile behavior among police officers.

The researcher was introduced to the chiefs of each police group so he could contact them in order to access their jurisdiction. Once there, the chief informed the officers that the researcher would be observing their daily activities and talk with them about their thoughts on their own functions and police department. During a period of 8 months, approximately four hours each day, we registered the behavior of individuals and groups of officers using written diaries, photographic archives, and video-recordings of the officers' work and activities, for example, in surveillance and radio posts, at the Police Academy, and during patrolling and civic ceremonies in public squares. Semi-structured interviews with 45 officers ( 30 men and 15 women) were also performed with a previously designed script focused on the following questions: What does it mean to be a police officer in Nezahualcóyotl? What are the attitudes and skills needed to be an officer in Nezahualcóyotl, and how are they acquired? What problems do most officers face? What gender differences are presented in the three aspects mentioned above? In all cases, the testimonies were anonymous, and participants were informed that they would only be used as part of this investigation and not have any consequence on their work, security, hierarchy and/or health.

Behavioral records and interviews were read and analyzed weekly in order to identify the main variables affecting the four general questions. The subsequent records were made according to the diversity of variables identified in the weekly analyses and it was stopped when these variables were observed as analogous. Before to perform the final analyses, we contrasted the officer's testimonies through interviews maintained with chiefs, with the director of the Police Academy and with the director of the Psychological Support Unit in Nezahualcóyotl. The final record was categorized by the researchers according to the content it presented.

\section{Results}

The meaning of being a police officer was accompanied by the attitudes and the training that officers consider they need to perform their work. For example, necessary attitudes are cooperativeness and impulsiveness, which are related to the meaning of an officer as an empathetic person and someone who takes risks. Most of these attitudes are learned during police practice or are part of family based and culturally inherited capabilities inserted in the historical representation of service within the police institution. Difficulties were mainly associated with hierarchical interactions inside the police department. Gender differences were identified in attitudes and problems that reflect a male domination within police performance similar than the national context observed in Mexico. Table 1 summarizes the results.

Results are presented in the following categorical firstperson analysis to illustrate the interpretations and shows translations of some of the officers' testimonies.

\section{Officers' Attitudes and Skills Needed in Nezahualcóyotl}

Officers indicated a sense of belonging to a group distinguished by attitudes of risk and impulsiveness:

"It is said that 'old police, do you asshole', but I do not apply it, only fools do not apply it. I like the mess and the action, I am very impulsive." (Man, 24 years old).

Also, officers mentioned qualities related to the concept of aid and service, as well as family variables that suggest that the decision to become an officer combines self-image with the opinions of others:

"What motivates me is my service to society. My wife does not like it, nor does my family. I have an eight yearold girl, and she likes the idea. But it is my job. I was always interested in being a policeman, because it is a way to be useful and help my society." (Man, 33 years old). 
Table 1. Summary of the Necessary Attitudes and Problems Mentioned by the Officers and Identified in the First-person Analysis from the qualitative Examination

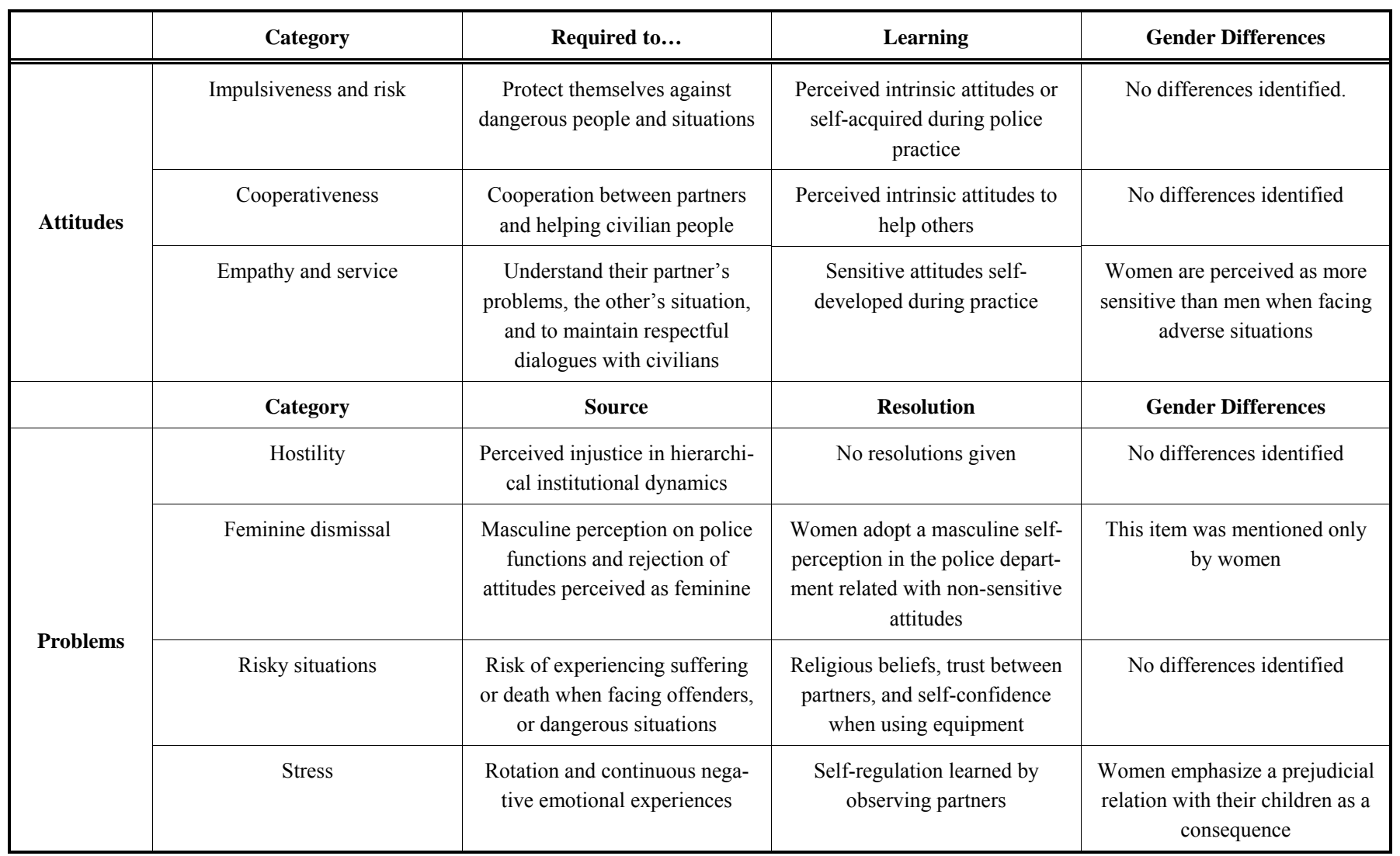

Two general types of motivation were distinguished. One represents an intrinsic motivation, which includes an aspiration defined in childhood, the continuation of a family tradition, or an image of service to the institution. The other type of motivation refers to an alternative source of income that does not require extensive training (three months) and education:

"A lot of individuals do not try to help others, they cannot become officers. The main attitude you need is wanting to help others." (Man, 33 years old).

"A normal person does not want to be a policeman. They are afraid. I came here because I had no other work, but then you love the uniform." (Man, 46 years old).

Recurrent criticism towards colleagues accompanied these testimonies and suggests that officers' attitudes are supported by moral judgments made on their partner's behavior:

"Before I thought it was a brotherhood where we stand together. But from the inside, you see a lot of fights between the officers. They fight among themselves, especially for incentives, but if all of us help to catch someone, we all deserve the incentive, and there is no reason to fight." (Man, 33 years old).

Even with disagreements between partners, officers view themselves as promoting social welfare and cooperation, which is linked with notions and experiences of "brother- hood", "pride", and/or morally unsuitable failing behaviors, as proposed in the moral emotion theory (Haidt, 2003).

In addition, adopting a police lifestyle involves experiences that activate basic biological systems for social adaptation, such as the fear and reality of death. For example:

"To be in full dress uniform, marks you as a thug's target. If you kill one of them you are done, outside and inside (of jail)." (Woman, 32 years old).

This last statement coincides with the constant confrontation with death that characterizes daily police activities and is reinforced by religious symbols that comfort police officers during their work. Examples of this are the altars at every surveillance post (see Fig. 2). However, the point is noteworthy when belief replaces the confidence that the officers perceive in their skills, in their tools and equipment, or in their institution:

"Really I trust more in the Virgin than in my chiefs. She takes better care of me." (Man, 34 years old).

\section{Problems Related with Stress and Unconformities}

Unconformities expressed by the officers included low salaries, long working hours, rotating schedules, and lack of equipment, training, and basic services that lead to health and work complications:

"We need equipment. We do not have patrol cars, or radios, or anything. If we have an injured person, how can I call an ambulance? If two or three bastards arrive, I 


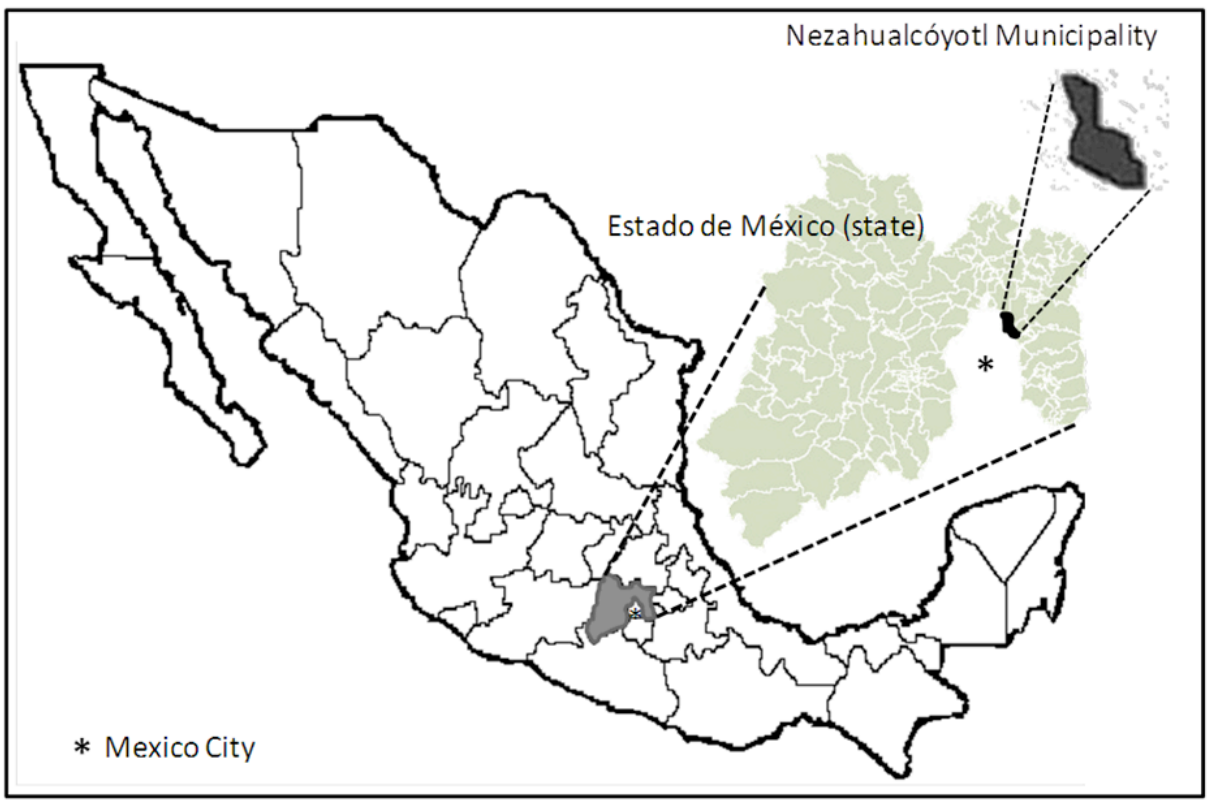

Fig. (1). Map of the Mexican Republic indicating Nezahualcóyotl Municipality in the state of Mexico. The asterisk locates Mexico City.

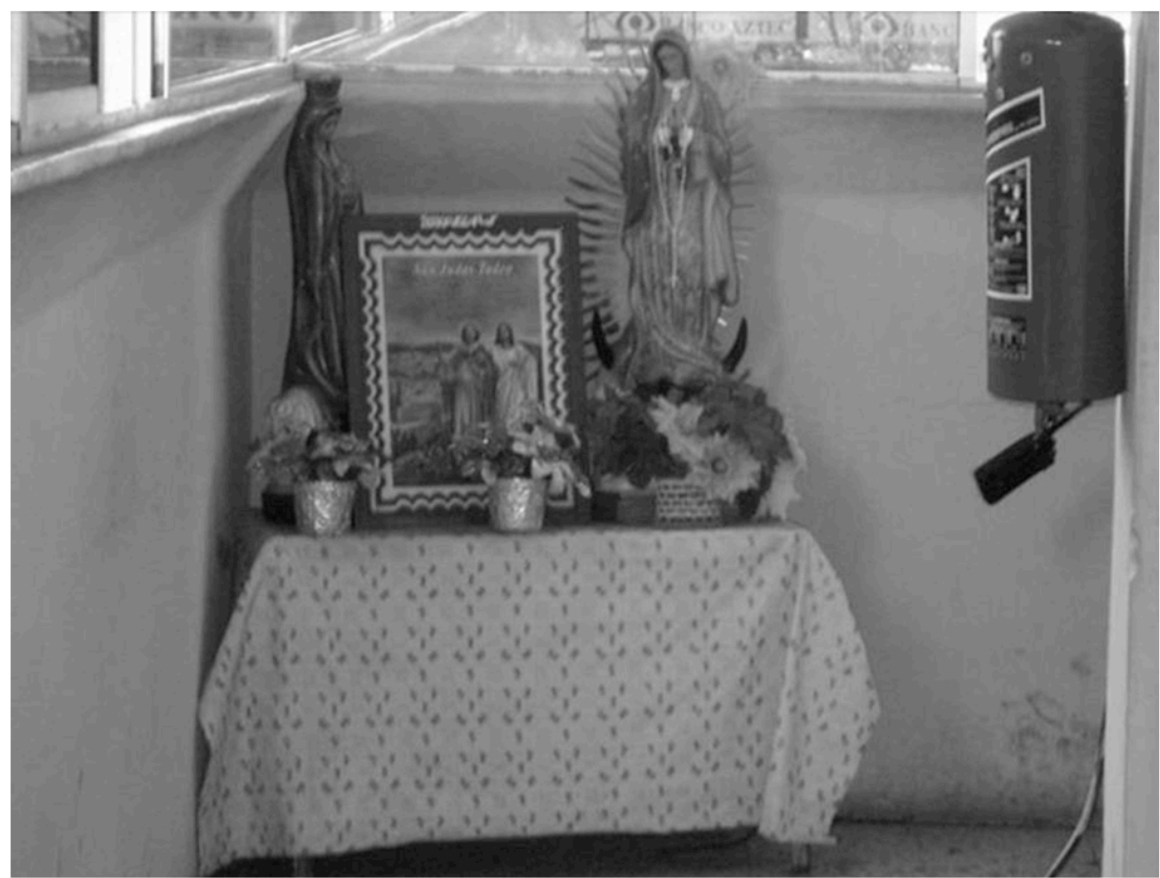

Fig. (2). The altars to the Virgin of Guadalupe are common in police posts and are frequently accompanied by diverse saints, depending on the particular devotion of each specific police group. In this image there are representations of the Virgin and San Judas Tadeo, the saint for "impossible causes" who also has numerous devout followers inside the police force.

give them the gun and take no chances." (Man, 31 years old).

Most stress was linked to relations with chiefs and injustices perceived in the hierarchy where subordinates must behave with discipline based on respect and loyalty to the chief. The notion of "chief" implies qualities not clearly perceived by the officers and may be due to inadequate se- lection systems. In fact, disagreement about chiefs was linked to a lack of recognition, of understanding, and of mutual credibility which does not reward the officers' actions. For example:

"They [the chiefs] do not recognize your work, which is unfair. We [the basic officers] are the ones who do the hard work." (Woman, 35 years old). 
Testimony was also given in relation to situations that have an impact on other fundamental areas of the officers' life, particularly relationships with their families:

"Sometimes you get home and you hurt the feelings of your family, because of the stress." (Man, 39 years old).

Also linked to family situations are stressful factors related to medical security. A "different" or "less professional" treatment was perceived once the medical personnel knew the person was a police officer:

"There must be a medical clinic for policemen. You can spend four hours waiting to be seen, and you can lose the whole day to go to the doctor or to take your children there, and they [the chiefs] comment on your absence." (Man, 36 years old).

Although there is a psychological support unit in the Nezahualcóyotl police department to attend the stressful and unsatisfactory factors identified here, its functions are varied and more related to personnel selection and evaluation; thus, it is difficult to obtain psychological assistance.

\section{Problems in Relation to Training and Civil Society}

Training is closely linked to the officers' skills and to the manner in which they learn and develop them. Officers recognized the lack of adequate training in basic skills, such as the use of weapons and a better physical condition, both necessary for optimizing health and performance and also safeguarding their life. Skills and "being the police" are two inseparable constructs in the self-perception of the officers:

"Discipline with the gun is missing. Officers think they are untouchable, because they have a weapon or because they have 'godparents' in the department, but when faced with danger, no godfather can help you." (Man, 32 years old).

Two officers (a man, 31 years old and a woman, 25 years old) manifested their training needs in the following order of need:

1. A gymnasium for exercise.

2. Law courses in order to not be cheated.

3. Courses to know how to deal with our personal problems.

4. Courses to improve trust between police partners.

5. Courses to control stress and someone with whom we can talk when we have a problem.

A notion of trust is needed between 2-member police teams because it is the "other member of the team" who, at any given time, can save the life of their partner and with whom he or she shares intimate personal situations, even equivalent to some types of parental unions. On the other hand, self-regulation involves emotional aspects, as well as learning legal concepts needed for policing (Mercadillo \& Barrios, 2011). In this sense, when asked about requesting a "law course in order to not be cheated", the officer pointed out that on occasions, while discussing possible illegal acts, civilians use legal vocabulary unknown to the officer. So, the officer cannot effectively argue the legality of the situation and: "Since we know that we are police, when we get angry we act in a superior manner" (Man, 31 years). Such reactions may occur during frustrating experiences classically linked to aggressive responses or humiliating experiences that elicit hostile attitudes and influence judgments and actions required for social decisions.

Police functions, skills, and training would have no sense outside the civilian context, since, historically, security organizations were created for the collective security of the public. It is from the civilian's perception that the judgments, which determine a "good" or a "bad" police officer, are defined. The following testimony illustrates how officers believe they are perceived by civil society:

"People see us as menacing! People are right, because many officers do not know how to speak well and they are despotic while in uniform." (Man, 33 years old).

When asked if they consider that this vision has changed, they replied:

"Yes, police were unpunished before. It has changed, but people don't know it." (Woman, 32 years old).

Relations between police and civil society are based on intersubjective mechanisms defined by the society's view of police and influenced by the officers' and civilians' perspectives about the cooperative attitudes and responsibilities linked to the historical meaning of service.

\section{Gender Differences}

Gender perspectives about the attitudes and skills point out that police are characterized by masculine representations in which women develop a more complex significance than men. For example:

"A lot of policemen do not want to patrol with women partners because, as they say: 'they have to take care of us'. But they must understand that the moment you join the patrol car it does not matter if you are a man or a woman. Even female officers do not understand this point, and they do not want to drive the car or to catch the thief. Look! There is only one female commander. Women do not need to be cared for. We only need our space and confidence. I am a group leader, and male coworkers are irritated because they were not chosen." (Woman, 32 years old).

Policing in Nezahualcóyotl includes a concept of masculinity linked to acts involving the use of physical force or requiring social authority, and a concept of femininity linked to empathic and sensitive attitudes classically differentiated in the Mexican culture (Ramos-Lira \& Saltijeral, 2008).

In relation to stress caused by family and work situations, women assume the role of mothers and housewives. Female officers work within a national Mexican culture that favors gender differences related to police requirements and problems:

"It would be fine to have a nursery for our children. My children are already old enough, but there are partners with very young children or babies. It is complicated to care for them, because of the schedules, especially when we have night duty, and the need to pay for someone to do it." (Woman, 31 years old). 


\section{QUANTITATIVE STUDY}

For the quantitative analysis, we selected six psychometric instruments that had been created or standardized in Mexico to assess relevant constructs expressed by the participants in reference to the attitudes needed to be a police officer into personality traits, attitudes and problems related with motivation, satisfaction in the work, hierarchical relations, and stress.

\section{Method}

\section{Participants}

215 police officers representing the 12 hierarchical categories existing in the police force, from officers to the commander-in-chief, were recruited ( 77 women, 138 men; age: $M=33.72$, S.D. $=1.68$; period of active service: $M=5.07$, S.D. $=2.53$ years). The procedure was designed according to the Ethical Principles proposed by the American Psychological Association (2002) and the Ethical Code for Psychologists in Mexico (Sociedad Mexicana de Psicología, 2009). The protocol was carried out under the ethical supervision of the Direction of the Department of Public Safety of Nezahualcóyotl and was approved by the Bioethical Committee in the Institute of Neurobiology of the Universidad Nacional Autónoma de México. Volunteers agreed to participate in an anonymous and confidential manner after the nature of the protocol was described.

\section{Instruments and Procedure}

Varimax rotations were obtained after the application of the four tests elaborated in Mexico to verify a similar factorial distribution and variance reported in the original instruments' construction. Cronbach's $\alpha$ coefficients were obtained for each test to determine reliability. The psychometric characteristics of the instruments can be revised in Calleja (2011), through the web portal of the Department of Psychology at the Universidad Nacional Autónoma de México.

All psychometric instruments were applied in group sessions of 10-12 officers using pencil and paper and were scheduled at similar times and under similar lighting conditions. The approximate time for each session was 2 hours.

The Motivation to Succeed Test (Calleja, 2011; La Rosa, 1986) was elaborated in a 1083 Mexican sample and evaluates the motivation to succeed, considered as the level of dominance and organization of the physical and social environment for overcoming obstacles and for maintaining work effectiveness. It includes 12 items assigned values in a rank from 1 to 5 , where " 1 " indicates "completely disagree" and " 5 " means "completely agree" with the item. Higher scores represent greater motivation to succeed. The test comprises three factors: Work, or motivation derived from the effort that the individual invests in his performance and the intrinsic satisfaction conferred by this effort (Cronbach's $\alpha=$ 0.84); Competition, or motivation elicited by dynamics involving antagonism (Cronbach's $\alpha=0.60$ ); Expertise, or motivation related to the level of skill achieved throughout his career (Cronbach's $\alpha=0.60$ ).

The Test for Attitudes toward the Work Leader's Characteristics and Performance (Calleja, 2011; Herrera-Caballero, 2001) was elaborated in a 414 Mexican sample and evaluates the workers' attitudes about the personal manners and abilities of their superiors or other individuals that are responsible for making decisions in their work. It includes 29 items describing the characteristics of the leader and assigns a value for each item within a range of 1 to 5 , where " 1 indicates that the statement does not describe this leader" and " 5 " indicates that the statement "describes this leader very well". Higher scores represent more positive attitudes toward the leader. The test comprises two factors: Attitudes toward the leader's performance (Cronbach's $\alpha=0.93$ ); and Attitudes toward the personal characteristics of the leader (Cronbach's $\alpha=0.96)$.

The Problematic Situations Test (Calleja, 2011; FloresGalaz, 1989) was elaborated in a 600 Mexican sample and evaluates circumstances that frequently cause difficulties in the individual's social interactions. It includes 28 items assigned a ranged value from 1 to 5 , where " 1 " means that the situation "always" presents difficulties, and "5" indicates that it "never" causes difficulties. Higher scores represent less problematic situations. The test comprises four problematic factors: Lack of courtesy and politeness (Cronbach's $\alpha=$ 0.84); Lack of decision (Cronbach's $\alpha=0.78$ ); Lack of respect and consideration (Cronbach's $\alpha=0.75$ ); Family issues (Cronbach's $\alpha=0.73$ ).

The Work Satisfaction Test (Calleja, 2011; ItoSugiyama, 1987) was elaborated with 250 Mexican samples and evaluates the degree of psychological well-being with respect to professional activities. It includes seven items ranked from 1 to 5 , where " 1 " means that the participant "completely disagrees" and "5" represents "completely agrees" with the item. Higher scores indicate greater work satisfaction. The test comprises two factors: Satisfaction with the chief (Cronbach's $\alpha=0.93$ ); Satisfaction with the characteristics of the work (Cronbach's $\alpha=0.80$ ).

The Temperament and Character Inventory designed by Clonninger, Svrakic \& Przybeck (Cloninger, Svrakic, \& Przybeck, 1993), and validated in Mexico (Cruz-Fuentes, López, Blas-Gracía, González, \& Chávez, 2005; GonzálezSantos, Mercadillo, Graff, \& Barrios, 2007), classifies personality in a psychobiological model. It includes 240 TrueFalse questions. The dimension Temperament, or inherited personality features, includes four factors: Novelty seeking, Harm avoidance, Reward dependence, and Persistence. The dimension Character or acquired personality traits includes: Self-direction, Cooperativeness, and Self-transcendence.

The Stress Profile proposed by Nowack (2002) evaluates the level of stress perceived and experienced by individuals. For this report, the factors representing Perceived stress, Social support, and Perceived psychological welfare were considered. The natural scores for the items comprising each factor are converted to percentiles, with $\mathrm{T}$ indicating the level of stress in a normal distribution. Scores rated in a $\mathrm{T} \geq$ 60 percentile for the Perceived stress factor are considered as high valuations may be related with health issues, and scores rated in a $T \leq 40$ percentile are considered as situations with reduced perceived stress. Scores rated in a $T \geq 60$ percentile for the Social support factor indicate high satisfactory experiences from family members, colleagues, and friends to help cope with the day-to-day police difficulties, and scores rated in a $\mathrm{T} \leq 40$ percentile are considered as reduced satis- 
factory experiences. Scores rated in a $T \geq 60$ percentile for the Psychological welfare factor represent a high level of well-being related to satisfaction and the ability to enjoy the aspects of their life in a comprehensive manner including family, friends, success, and work, while scores rated in a T $\leq 40$ percentile are considered as generalized experiences indicating a lack of welfare.

\section{Statistical Analysis}

The database and statistical analyses were carried out with the SPSS 17.0 program. Means for the total measure ratings and the factors included in each test were obtained.

Scores in the Temperament and Character Inventory were compared with the Mexican civilian ratings previously reported by applying a Student's $t$-test. The frequency cases for the Perceived stress, Social support, and Perceived psychological welfare factors in the Stress Profile were described as high ( $T \geq 60$ percentile), medium ( $T=41-59$ percentile), and reduced ( $\mathrm{T} \leq 40$ percentile) scores.

Analyses of variance and post hoc HDS Tukey test were performed between the factors included in The Work Satisfaction Test, The Test for Attitudes toward the Work Leader's Characteristics and Performance, The Motivation to Succeed Test, and The Problematic Situations Test to identify statistical differences.

Gender differences were analyzed using the Student's $t$ test comparing the mean obtained for women and men. Correlations between the factors integrating each test and correlations between the test results and the officers' level of education, hierarchy, and time of active service were also calculated by applying Pearson's coefficients.

\section{Results}

When comparing Mexican police officers and civilians, the only significant difference in the Temperament and Character Inventory was a lower score in the Selftranscendence factor $\left(\mathrm{t}_{273}=2.27, p=0.05\right)$ (see Fig. 3 ).

Results for the Stress Profile indicate that many officers perceived reduced support from society $(n=95 / 215)$, slightly more perceived moderate support $(n=104 / 215)$, and only a small number of officers $(n=16 / 215)$ experienced a satisfactory support. A vast majority of the sample $(\mathrm{n}=$ 160/215) indicated high psychological well-being. Most of the officers reported a reduced perceived stress $(\mathrm{n}=$ $134 / 215$ ), and only a few reported health disturbances linked to stress $(n=5 / 215)$ (see Fig. 4). Psychological well-being scores were negatively correlated with Perceived stress $\left(r_{215}\right.$ $=-0.137, p=0.05$ ) and positively correlated with the Work satisfaction factor of the Work Satisfaction Test $\left(r_{215}=\right.$ $0.154, p=0.05$ ).

The analysis of variance between the factors of the Motivation to Succeed Test showed differences $\left(F_{2,619}=303.75\right.$, $p<0.01$ ) indicating that the main source of motivation is the Work factor (see Table 2). The Work factor was positively correlated with the educational level $\left(r_{215}=0.239, p<0.05\right)$ and with hierarchy $\left(r_{215}=0.151 \mathrm{p}<0.01\right)$.

In the Test of Attitudes towards the Work Leader's Characteristics and Performance (see Table 2) no differences were observed between factors. The personal chief's attributes showed gender differences $\left(t_{213}=2.08, p<0.05\right)$, with women granting more favorable ratings. The time of active service was negatively correlated with both personal $\left(r_{215}=\right.$ $0.168, \mathrm{p}<0.05)$ and professional $\left(r_{215}=-0.181, \mathrm{p}<.05\right)$ factors of the test.

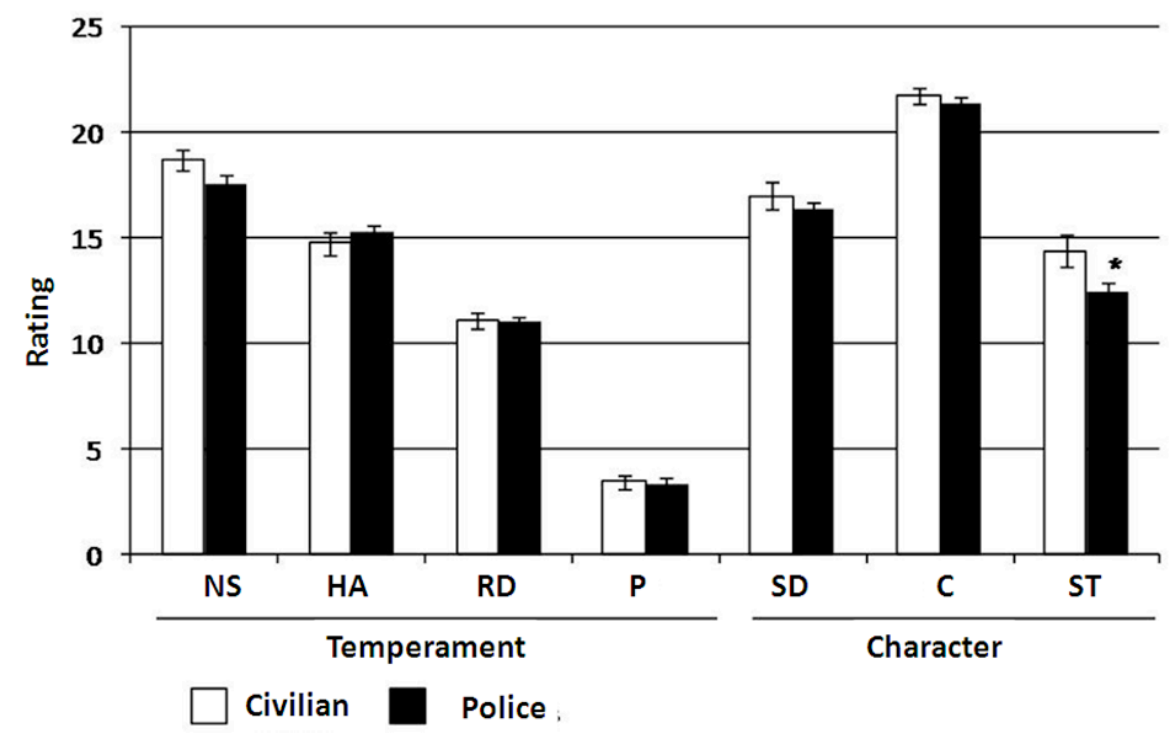

Fig. (3). Mean of the dimensions included in the Temperament and Character Inventory rated in the police sample and in the civilian sample used for the Mexican validation of the test. NS: Novelty Seeking, HA: Harm Avoidance, RD: Reward Dependence, P: Persistence, SD: Selfdirection, C: Cooperativeness, ST: Self-transcendence. Standard error is showed at the top of each column. *Indicates significant differences at $p=0.05$ between the civilian and the police samples when the Student's $t$-test was applied. 
Scores for the Work Satisfaction Test were close to the neutral point (see Table 2). Women reported less satisfaction with their chiefs than with the working conditions, and higher levels of satisfaction than men in both the total score $\left(t_{213}=2.04, p<0.05\right)$ and with work characteristics $\left(t_{213}=\right.$ $3.73, p<0.05)$. Work satisfaction scores correlated positively with scores evaluating the chiefs' performance $\left(r_{215}=\right.$ $0.586, p<0.01)$.

For the Problematic Situations Test significant differences between the factors were identified $\left(F_{4,1074}=23.39, p\right.$
$<0.01)$. Lack of respect and Lack of decision were noted as two statistically similar factors (see Table 2).

\section{DISCUSSION}

Police officers manifested lower scores than civilians in the Self-transcendence factor of the Temperament and Character Inventory (TCI), which refers to intuitive understandings of moral and empathic elements, such as ethics. This presents an important difference when compared to reports from other countries (Du Preez, Cassimjee, Ghazinour,

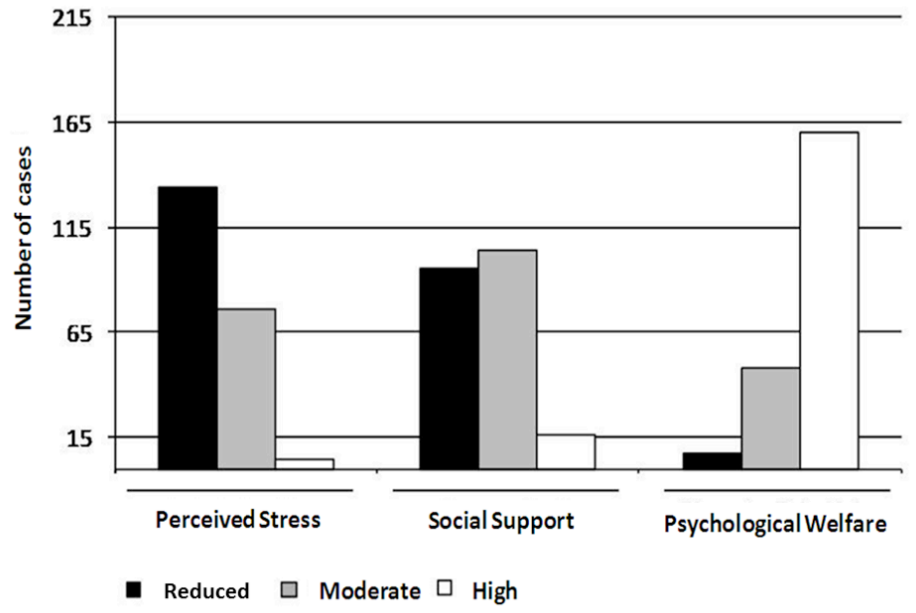

Fig. (4). Frequencies of the ratings obtained for the police sample in the dimensions included in Stress Profile.

Table 2. Mean $(M)$ and Standard Deviation (S.D.) Obtained in the Police Sample $(n=215)$ for the Total Scores and Factors of the Mexican test Applied in the Psychometric Evaluation

\begin{tabular}{|c|c|c|c|c|c|c|c|}
\hline Test & Factors & \multicolumn{2}{|c|}{ Women } & \multicolumn{2}{|c|}{ Men } & \multicolumn{2}{|c|}{ All } \\
\hline \multirow{2}{*}{ Motivation to Succeed ${ }^{* *}$} & Work $_{b}$ & 4.44 & 0.46 & 4.51 & 0.48 & 4.49 & 0.48 \\
\hline & Expertise $_{\mathrm{c}}$ & 4.16 & 0.54 & 4.21 & 0.45 & 4.19 & 0.48 \\
\hline \multirow[t]{3}{*}{ Leader's Characteristics } & Personal * & 3.47 & 0.89 & 3.18 & 1.05 & 3.28 & 1 \\
\hline & Performance & 3.51 & 0.94 & 3.25 & 1 & 3.34 & 0.99 \\
\hline & Total * & 3.64 & 1.21 & 3.28 & 1.04 & 3.41 & 1.16 \\
\hline Work Satisfaction & Chief & 3.72 & 1.11 & 3.75 & 0.64 & 3.74 & 0.83 \\
\hline \multirow[t]{4}{*}{ Problematic Situations** } & Family a & 3.9 & 0.96 & 4.05 & 0.83 & 4 & 0.88 \\
\hline & Lack of courtesy $c$ & 3.25 & 0.83 & 3.3 & 0.76 & 3.28 & 0.78 \\
\hline & Lack of decision $_{b}$ & 3.7 & 0.76 & 3.81 & 0.76 & 3.77 & 0.76 \\
\hline & Lack of respect $b$ & 3.72 & 0.76 & 3.77 & 0.77 & 3.77 & 0.76 \\
\hline
\end{tabular}

Note: For all cases, items were ranked from 1 to 5 , where "1" represented the lowest value in the test and " 5 " the highest. **Significant differences between factors $(p \leq 0.05)$ included in the test based on ANOVA. *Significant gender differences $(p \leq 0.05)$ in the factor or in the total scores based on the Student's $t$ test. Different subscripts $(\mathrm{a}, \mathrm{b}, \mathrm{c})$ indicate significant differences between factors after the post hoc HDS Tukey test was applied. 
Lauritz, \& Richter, 2009). According to the information provided by in the interview with the director of the Psychological Support Unit, this result is understandable when considering that the violence and socioeconomic issues in the centre of Mexico have elicited a lack of interest in policing, hence softening the strict criteria to select candidates for municipal police in Nezahualcóyotl.

As presented in the ethnographic analysis, some of the fundamental attitudes needed to be a police officer are impulsiveness and a willingness to take the risks needed to maintain an officer's status and to safeguard his/her life in physical and social environments perceived as hostile (Twersky-Glasner, 2005). The officers also view themselves as developers of social welfare and cooperation. Optimally, these qualities would be reflected in high levels of the Novelty seeking and the Cooperativeness factors of the TCI, but these were not identified at all. The inconsistency with respect to risk may indicate that the officers' interpretation about their adverse experiences leads to attitudes and emotions being represented in acceptable ways (Frewin, Stephens, \& Tuffin, 2006), such as is required in hostile environments in Nezahualcóyotl. With regard to cooperation, the qualities described by the officers may reflect a selfperception based on a social desirability that keeps the historical image of policing linked to social welfare in Mexico (Cruz, 2007).

Results on the Motivation to Succeed Test indicate that the main source of motivation is the Work factor or the intrinsic satisfaction experienced while policing. Neither the Expertise nor the Competition factors are the main sources of motivation since, as presented in the qualitative approach, both are linked to inadequate training and with hierarchal decisions not based on merit and perceived as unjust.

The lack of motivation based on merit contrasts with the positive correlation between the Work factor and the educational level and hierarchy. These correlations suggest that chiefs or superior officers have more education, and have invested more personal effort in their work to obtain an upper-level position. So the notion of "chief" implies qualities not clearly perceived by the officers and the perception of hierarchical unfairness could be related to opaque or inadequate selection systems, not necessarily to the lack of merit (Cunningham, Jones, \& Behrens, 2011).

Results about the Test of Attitudes towards the Work Leader's Characteristics and Performance, agree with ethnographical data showing that the judgments about the chiefs are based on their honesty and treatment of their subordinates. They also suggest that a longer time of service in the department is accompanied by a less favorable rating of the chiefs. Women granted more favorable ratings than men, so the perception of gender inequality could be linked to a widespread doubt that women can perform the typical functions such as patrolling or obtaining a commander degree, but is not linked to the chief's attitudes.

Work satisfaction scores were positively correlated with the chiefs' performance, but not with scores for the Motivations for Success Test. Satisfaction elicited by the policing work and the perception of the chief's qualities are two factors linked to the congruence expected between proper police performance and the recognition of merit, which may imply an extrinsic variable strengthened by the recognition of officers' performance in police departments and by civilians (Sanders, 2010).

The lack of courtesy for adequate relationships with civilians was indicated in the qualitative analysis, but had little effect on interpersonal relationships in the psychometric evaluation. Relevant scores in the family issues factor of the Problematic Situations Test are consistent with the ethnographical data alluding to family difficulties.

Family situations were identified as a cause of stress in conjunction with the attitudes of their chiefs and the lack of training in the qualitative analysis. Some physical and emotional situations reported by the Psychological Support Unit of the Department of Public Safety of Nezahualcóyotl, such as gastritis or negative emotions, are associated with stress symptoms. Thus, the reduced perception of stress and the high psychological well-being evaluated by the Stress Profile do not necessarily indicate the absence of stress but might point out that, since police officers have not been trained on how to cope with stress, they perform strategies learned intuitively within the police culture, which influences the subjective perception on stressful situations. Although gender differences in the stress perceived by officers have been reported (Gächter, Savage, \& Torgler, 2011), the lack of differences in this study suggests similar perceptions in both genders.

As observed in the ethnographic analysis, police is characterized by masculine representations in which women develop a more complex significance than men (Carlan, Nored, \& Downey, 2011). Similar to other Latin-American countries, gender issues within this context are related to national realities and cannot be considered as isolated but as part of a national difference in representation although adapted to this particular context (Rodriguez, 2007).

Also related to national realities and stress, the officers' constant confrontation with death is faced through religious symbols that comfort the police officers during their work (Osofsky \& Osofsky, 2002). The more noticeable symbols in our study, the Virgin of Guadalupe and San Judas Tadeo, constitute historical representations of protection emphasized in poor and hostile environments such as Nezahualcóyotl municipality (Hernández-Hernández, 2011). The perceived lack of protection is also illustrated when officers manifest hostile social environments and humiliating experiences that elicit aggressive reactions. Similar to other Latin-American countries, this situation may be linked to a generally unfavorable perception of policing, reflected in institutional and national violence against police officers, which influences their own learning and actions and how they perceive the rights of others and ethical premises (Cabeleira de Moraes, 2007; Suárez de Garay, 2006).

\section{CONCLUSIONS}

Officers' perception of the circumstances in Nezahualcóyotl is filtered through social cognitive mechanisms such as pride, loyalty, courage, service, and cooperation that influence in their actions and notions. It also includes a perception of injustice during the selection process for promotion. However, the perceived inequity in promotion of hierarchies 
could refer to the way in which the system is run, even though this system does select individuals with the appropriate characteristics.

Some officers' situations are typically associated with stress, such as cardiovascular diseases, long working hours, sleep deprivation, somatization, irritability, and experiences of injustice and abuse, the psychometrical evaluation indicates reduced levels of perceived stress and high levels of psychological well-being. This apparent inconsistency is fundamental for the creation of training programs on stress management, since it would imply the control of a variable that the individuals do not perceive as risky. It could also involve not only the work itself, but a life style for which the officers have been trained and adapted (Carlan \& Nored, 2011).

Relations between police and civil society are based on inter-subjective mechanisms defined by the society's view and influenced by the officers' and civilians' perspectives. This definition constitutes part of the human social cognition (Beer \& Ochsner, 2006), influences the cooperative attitudes toward inferred and perceived needs (Mercadillo \& Arias, 2010), and shows an officer's responsibility linked to a social empathy or set of abilities to respond to social needs based on both institutional codes and individual judgments.

The confrontation with offenders, the perception of injustice, and the lack of institutional protection and recognition are associated with uncomfortable experiences related to anger and fear that may elicit inappropriate behaviors (Javela, Mercadillo, \& Ramirez, 2008). In this sense, social intersubjectivity is relevant since officers have legitimate permission to use coercion as a means of social justice and order; thus, it becomes necessary to have institutional supervision (Miller, 2004), as well as training in interpersonal skills, and regulation of moral emotions such as guilt, shame or anger, which can be elicited by the apparent inconsistency between the use of coercion and the promotion of order, justice, and peace (Jesilow \& Parsons, 2000). Some reform proposals in Mexico could be directed to consider police officers as social educators of values based on local identities (Frühling, 2012; Ungar \& Salomón, 2012).

The few gender differences observed in the psychometric assessment suggest that motivation, problematic situations, and stress affect both genders similarly and perhaps reflect a homogenized police culture. However, there are situations related to national problems, for example, the almost exclusive role of women in the care of children and the home, or the difficulty for women to penetrate an environment with typically masculine attributes. Therefore, training programs and dynamics for police intervention not only should involve the role of the police culture but must also be consistent with national realties and attitudes (Corsianos, 2011).

Officers' intrinsic motivation related with service could be linked to human motivational systems denoting aid, empathy, and the welfare of others (Mercadillo \& Arias, 2010), which are values previously identified in Mexican police officers but not used and nor reinforced in institutional programs and training (Larose et al., 2010).

Interdisciplinary approaches for studying officers' behavior encourage a more complete understanding of how the officers internalize and apply the premises presented in police reform proposals. This idea is crucial since, although the efforts to improve policing are made primarily by the government, it is the officers who experience the consequences of corruption and other problems. Data generated from ethnological and psychosocial frameworks consider elements based on cognitive systems, and constitute a semiotic condition by connecting the officers' behavior with the sense that they have of themselves, of their institution and of society.

\section{CONFLICT OF INTERESTS}

No conflict of interest is declared.

\section{ACKNOWLEDGEMENTS}

This study was supported by a financial contribution from the Municipality of Ciudad Nezahualcóyotl, Mexico, and the scholarship CONACYT No. 213635. We thank Dr. Dorothy Pless and Paulina M. Barrios for the revision of the manuscript. Leopoldo González-Santos, and Juan J Ortiz, Institute of Neurobiology, Universidad Nacional Autónoma de México, for their technical support. We also appreciate the financial support and operational facilities provided by Mr. Jorge Amador Amador, Director of the Department of Public Safety of Nezahualcóyotl, Ana Lilia Torres Bárcenas, head of the Psychological Support Unit of the Public Safety Department of Nezahualcóyotl, and the police officers who kindly volunteered to participate in this research.

\section{REFERENCES}

Aranda-Beltran, C., Pando-Moreno, M., Salazar-Estrada, J. G., TorresLopez, T. M., \& Aldrete-Rodriguez, M. G. (2009). Social support, burnout syndrome and occupational exhaustion among Mexican traffic police agents. The Spanish Journal Psychology, 12(2), 585592.

American Psychological Association. (2002). Ethical principles of psychologist and code of conduct. American Psychologist, 57, 10601073 .

Beer, J. S., \& Ochsner, K. N. (2006). Social cognition: a multi level analysis. Brain Research, 1079(1), 98-105.

Cabeleira de Moraes, M. (2007). La violencia contra los policías: percibir, problematizar y actuar. In H. Caruso, J. Muniz \& A. CarballoBlanco (Eds.), Policía, estado y sociedad: prácticas y saberes latinoamericanos (pp. 351-355). Río de Janeiro: Publit.

Calleja, N. (2011). Inventario de escalas psicosociales en México $1984-$ 2005. México: Universidad Nacional Autónoma de México, accesible in: http://www.psicologia.unam.mx/contenidoEstatico/archivo/files/Investigaci\%C3\%B3n/Nazira\%20Calleja\%20Inventario $\%$ 20de $\% 20$ escalas $\% 20$ psicosociales $\% 20$ en $\% 20 \mathrm{M} \%$ C3\%A9xico, $\% 20$ 1984-2005.pdf

Carlan, P. E., \& Nored, L. S. (2011). An examination of officer stress: Should police departments implement mandatory counseling? Journal of Police and Criminal Psychology 23(1), 8-15.

Carlan, P. E., Nored, L. S., \& Downey, R. A. (2011). Officer preferences for male backup: The influence of gender and police partnering Journal of Police and Criminal Psychology, 26(1), 4-10.

Cloninger, C. R., Svrakic, D. M., \& Przybeck, T. R. (1993). A psychobiological model of temperament and character. Archives of General Psychiatry, 50(12), 975-990.

Corsianos, M. (2011). Responding to officers' gendered experiences through community policing and improving police accountability to citizens. Contemporary Justice Review: Issues in Criminal, Social, and Restorative Justice, 14(1), 7-20.

Cruz-Fuentes, C., López, L., Blas-Gracía, C., González, L., \& Chávez, R. (2005). Datos sobre a validez y la confiabilidad de la sympom check list (sc190) en una muestra de sujetos mexicanos. Salud mental, 28(1), 72-81.

Cruz, L. C. (2007). Seguridad Pública (2 ed.). México: Trillas. 
Cunningham, M. R., Jones, J. W., \& Behrens, G. M. (2011). Psychological Assessment of Chief of Police Candidates: Scientific and Practice Issues. Journal of Police and Criminal Psychology, 26(2), 77-86.

Charmaz, K. (2005). Grounded theory in the 21 st Century. In N. K. Denzin \& Y. S. Lincoln (Eds.), The Sage handbook of qualitative reserach (pp. 507-535). Thousand Oaks, CA: SAGE.

Du Preez, E., Cassimjee, N., Ghazinour, M., Lauritz, L. E., \& Richter, J. (2009). Personality of South African police trainees. Psychological Reports, 105(2), 539-553.

Escalante, F. (2009, Septiembre 2009). Homicidios 1990-2007. Nexos, $25-$ 31.

Flores-Galaz, M. (1989). Asertividad, agresividad y solución de situaciones problemáticas en una muestra mexicana. Unpublished $\mathrm{PhD}$ thesis. Universidad Nacional Autónoma de México, México.

Frewin, K., Stephens, C., \& Tuffin, K. (2006). Re-arranging Fear: Police Officers' Discursive Constructions of Emotion. Policing and Society, 16(3), 243-260.

Frühling, H. (2012). A realistic look at Latin American community policing programmes. Policing and Society, 22(1), 76-88.

Gächter, M., Savage, D. A., \& Torgler, B. (2011). Gender variations of physiological and psychological strain amongst police officers. Gender Issues, 28(1-2), 66-93.

González-Santos, L., Mercadillo, R. E., Graff, A., \& Barrios, F. A. (2007). Versión computarizada para la aplicación del Listado de Síntomas 90 (SCL 90) y del Inventario de Tempramento y Carácter (ITC). Salud Mental, 30(4), 31-40.

Haidt, J. (2003). The moral emotions. In R. J. Davidson, K. Scherer \& H. Goldsmith (Eds.), Handbook of affective sciences (pp. 852-870). Oxford: Oxford University Press.

Hernández-Hernández, A. (2011). Devoción a la Santa Muerte y San Judas Tadeo en Tepito y anexas. El Cotidiano, 169, 39-50.

Herrera-Caballero, J. (2001). Actitudes de un grupo de trabajadores hacia sus líderes, dentro de un sistema de seguridad social. Unpublished $\mathrm{PhD}$ thesis. Universidad Nacional Autónoma de México, México.

Hollan, D., \& Throop, J. C. (2008). Whatever Happened to Empathy?: Introduction. Ethos, 36(4), 385-401.

Ito-Sugiyama, M. E. (1987). Influencia de variables familiares y laborales en la satisfacción de mujeres profesionistas con su trabajo. Unpublished PhD thesis. Universidad Nacional Autónoma de México, México.

Javela, J. J., Mercadillo, R. E., \& Ramirez, J. (2008). Anger and associated experiences of sadness, fear, valence, arousal, and dominance evoked by visual scenes. Psychological Reports, 103(3), 663-681.

Jesilow, P., \& Parsons, D. (2000). Community policing as peacemaking. Policing and Society, 10(2), 163-182.
La Rosa, J. (1986). Escalas de locus de control y autoconcepto: construcción y validación. Unpublished $\mathrm{PhD}$ thesis. Universidad Nacional Autónoma de México, México.

Larose, A. P., Maddan, S., \& Caldero Ali Mathe, M. (2010). Value change among police recruits in Mexico at a time of organizational reform: A follow-up study ssing rokeach value indicators. International Journal of Comparative and Applied Criminal Justice, 34(1), 5377.

Mercadillo, R. E., \& Arias, N. (2010). Violence and compassion: a bioethical insight into their cognitive bases and social manifestations. International Social Science Journal, 61(200-201), 221-232.

Mercadillo, R. E., \& Barrios, F. A. (2011). Brain correlates of impulsivity in police officers: A neurocognitive and ethnological exploration. The Open Criminology Journal, 4(S 2-M3), 54-60.

Miller, L. (2004). Good cop-Bad cop: Problem officers, law enforcement culture, and strategies for success Journal of Police and Criminal Psychology, 19(2), 30-48.

Nowack, K. M. (2002). Perfil de estrés (A. Jiménez, Trans.). México: Manual Moderno.

Osofsky, M. J., \& Osofsky, H. J. (2002). The psychological experience of security officers who work with executions. Psychiatry, 65(4), 358370.

Ramos-Lira, L., \& Saltijeral, T. (2008). Violencia episódica o terrorismo íntimo? Una propuesta exploratoria para clasificar la violencia contra la mujer en las relaciones de pareja. Salud Mental, 31(6), 469478.

Rodriguez, E. (2007). El enfoque de género en la formación de la policía nacional de Nicaragua. In H. Caruso, J. Muniz \& A. CarballoBlanco (Eds.), Policia, estado y sociedad: prácticas y saberes latinoamericanos (pp. 363-368). Río de Janeiro: Publit.

Sanders, B. A. (2010). Police chief perceptions of good policing in nonurban departments. Journal of Crime and Justice, 33(1), 117-135.

Sociedad Mexicana de Psicología. (2009). Código Ético del Psicólogo. México: Trillas.

Suárez de Garay, M. (2006). Los policías: una averiguación antropológica. Guadalajara, Méx: ITESO.

Tello, N. (2011). Police reforms: the voice of police and residents in Mexico City. Policing and Society, 22(1), 14-27.

Toch, H. (2008). Police officers as change agents in police reform. Policing and Society, 18(1), 60-71.

Twersky-Glasner, A. (2005). Police personality: What is it and why are they lake that. Journal of Police and Criminal Psychology, 20(1), 56-67.

Ungar, M., \& Salomón, L. (2012). Community policing in Honduras: local impacts of a national programme. Policing and Society, 22(1), 2842.

van Reenen, P. (2010). From policing the garbage can to garbage can policing. Policing and Society, 20(4), 459-479.

Received: June 14, 2012

Revised: October 23, 2012

Accepted: October 25, 2012

(C) Mercadillo et al.; Licensee Bentham Open.

This is an open access article licensed under the terms of the Creative Commons Attribution Non-Commercial License (http://creativecommons.org/licenses/by-nc/3.0/) which permits unrestricted, non-commercial use, distribution and reproduction in any medium, provided the work is properly cited. 